\title{
Different signaling pathways involved in the anti-inflammatory effects of unfractionated heparin on lipopolysaccharide-stimulated human endothelial cells
}

\author{
Xu Li (iD, Lu Li, Yuequan Shi, Sihan Yu and Xiaochun Ma*
}

\begin{abstract}
Background: There is a complex interplay between inflammatory response and coagulation in sepsis. Heparin is used as a recognized anticoagulant and possesses multiple biological properties that possibly affect sepsis. This study aimed to determine the possible signaling pathways involved in the anti-inflammatory effects of unfractionated heparin (UFH) on lipopolysaccharide (LPS)-stimulated human pulmonary microvascular endothelial cells (HPMECS).

Methods: HPMECs were transfected with siRNA targeting $\mid \mathrm{kB}-\mathrm{a}$. Cells were treated with UFH $(0.01 \mathrm{U} / \mathrm{ml} \sim 10 \mathrm{U} / \mathrm{ml})$ $15 \mathrm{~min}$ before adding LPS $(10 \mu \mathrm{g} / \mathrm{ml})$. We detected the markers of systemic inflammatory response. Release of interleukin (IL)-6, IL-8 were evaluated at $3 \mathrm{~h}$ by ELISA and at $1 \mathrm{~h}$ by qRT-PCR. After $1 \mathrm{~h}$, nuclear factor-KB (NF-KB) as well as phosphorylated inhibitor KB-a (IKB-a), signal transducer and activator of transcription-3 (STAT3) and ERK1/2, JNK, p38 mitogen-activated protein kinase (MAPK) expressions were evaluated by Western blot. DNA binding was conducted to further prove the activation of NF-KB pathway.

Results: In HPMECs, UFH obviously inhibited LPS-stimulated production of IL-6 and IL-8, especially in $10 \mathrm{U} / \mathrm{ml}$. UFH inhibited LPS-induced phosphorylation of IKB-a, ERK1/2, JNK, p38 MAPK and STAT3. UFH also suppressed LPSstimulated nuclear translocation of NF-kB. Importantly, transfection with siRNA targeting IkB-a induced more obvious inflammatory response. UFH suppressed cytokines production and phosphorylation of different signaling pathways in IKB-a silencing cells.
\end{abstract}

Conclusion: These results demonstrate that UFH exerts the anti-inflammatory effects on LPS-stimulated HPMECs by different signaling pathways.

Keywords: Unfractionated heparin, Sepsis, Endothelial cells, Signaling pathway, Nuclear factor-kB

\footnotetext{
*Correspondence: vincentzh002@outlook.com; Ix2008yy@gmail.com Department of Critical Care Medicine, the First Affiliated Hospital, China Medical University, North Nanjing Street 155, Shenyang 110001, Liaoning Province, People's Republic of China
}

(c) The Author(s). 2020 Open Access This article is distributed under the terms of the Creative Commons Attribution 4.0 International License (http://creativecommons.org/licenses/by/4.0/), which permits unrestricted use, distribution, and reproduction in any medium, provided you give appropriate credit to the original author(s) and the source, provide a link to the Creative Commons license, and indicate if changes were made. The Creative Commons Public Domain Dedication waiver (http://creativecommons.org/publicdomain/zero/1.0/) applies to the data made available in this article, unless otherwise stated. 


\section{Introduction}

Sepsis is a complicated clinical syndrome in which the innate host immune response interacts with invading pathogen. There is a complex interplay between inflammatory response and coagulation in sepsis. Release of inflammatory mediators activates the coagulation system, which in turn promotes inflammation through multiple ways, leading to multiple organ dysfunction syndrome (MODS) [1]. Endothelial cells are the monolayer of cells that are located on the inner surface of all blood vessels. They play a major role in host responses during sepsis. Normally, the endothelium acts as a barrier between immune cells and infection or inflammation. However, the properties of endothelial cells in large and microvessels are different. Especially microvascular endothelial cells play an important role in the process of sepsis. Exposure to inflammatory mediators causes the endothelium to activate and become pro-coagulatory and pro-inflammatory [2]. And it is becoming more and more clear, that vice versa, factors of the coagulation system can significantly modulate the inflammatory reaction [1, 3]. An amplified response, however, can result in multiple organ dysfunction and even death. Thus, the agents that suppress the activation of both coagulation and inflammation may improve the prognosis in sepsis.

The anticoagulant properties of unfractionated heparin (UFH) are well established [4]. In these years, more and more attention has been paid to the anti-inflammatory and immunomodulatory effects of UFH [5-10]. As a consequence, UFH has the potential to become a new therapeutic drug for specific group of septic patients. However, the precise mechanism of action is not yet fully elucidated. Our previous studies have shown that UFH suppressed LPS-induced inflammatory mediator production in endothelial cells [8-10]. Whereas, the related mechanisms between anti-inflammatory action and organ protection have not been well documented. This study aimed to further assess the effect of UFH on production of inflammatory markers and the involved signaling pathways in Human Pulmonary Microvascular Endothelial Cells (HPMECs).

\section{Materials and methods}

\section{Endothelial cells culture and treatment}

HPMECs, endothelial cell growth supplement (ECGS) and endothelial cell medium (ECM) were from ScienCell Research Laboratories. HPMECs were cultured in ECM supplemented with 1\% ECGS, 5\% fetal bovine serum (FBS) and 1\% penicillin/streptomycin solution. The cells were cultured at $37^{\circ} \mathrm{C}$ in $5 \% \mathrm{CO}_{2}$. Experiments were conducted with cells at passages 3 to 5 . Before each experiment, the cells were rested for $1 \mathrm{~h}$ in ECM containing $1 \%$ ECGS, 1\% FBS and 1\% penicillin/streptomycin solution. After incubation, endothelial cells were washed with phosphate-buffered saline (PBS) (PH 7.4) for three times to exclude heparin residues. LPS (LPS from Escherichia coli strain 0111:B4, Sigma) was used at $10 \mu \mathrm{g} / \mathrm{ml}$. The cells were either exposed to LPS alone or in combination with different concentrations of UFH (Shanghai NO.1 Biochem-istry \& pharmaceutical Co., China) as specified in the text when they reached $90 \%$ confluence.

\section{Cell viability}

The cell viability was evaluated by methyl thiazoyltetrazolium (MTT) assay. HPMECs were seeded in 96-well plates at a density of $1-2 \times 10^{4}$ cells/well. Briefly, at the indicated time after the treatment with or without UFH before exposure to LPS for $24 \mathrm{~h}$, the culture supernatant was removed. The cells were washed with PBS and incubated with $200 \mu \mathrm{l}$ medium containing $20 \mu \mathrm{l}$ of MTT (1 $\mathrm{mg} / \mathrm{ml}$ ) at $37^{\circ} \mathrm{C}$ for $4 \mathrm{~h}$. The medium was then aspirated and $150 \mu \mathrm{l}$ of dimethyl sulfoxide (DMSO) per well was added for formazan solubilization. The absorbance of converted dye was measured at a wavelength of $490 \mathrm{~nm}$ using a microplate reader. The viability of HPMECs in each well was presented as percentage of control cells.

\section{Transient transfection and RNA interference}

Pre-validated siRNA for human IkB- $\alpha$ (accession number sc-29360) and a negative control (accession number sc-44231) were obtained from Santa Cruz Biotechnology (Santa Cruz, CA, USA). HPMECs at a density of $1 \times 10^{6}$ cells were transfected at $70 \%$ confluence with a final concentration of $25 \mathrm{nM}$ either IkB- $\alpha$ siRNA or a scramble control using TransIT-TKO transfection reagent (Mirus, Madison, WI) according to the manufacture's instructions. HPMECs were cultured for $24 \mathrm{~h}$ after transfection and then stimulated with LPS in the presence or absence of varying concentrations of UFH for indicated time, or with UFH alone. UFH was added to cells $15 \mathrm{~min}$ prior to stimulation with LPS. The efficiency of gene silencing of $I \kappa B-\alpha$ was determined by western blot and immunofluorescence.

\section{Enzyme-linked immunosorbent assay (ELISA) for IL-6 and IL-8}

HPMECs were treated with UFH 15 min and then exposed to LPS for $3 \mathrm{~h}$. The content of IL- 6 and IL- 8 in the supernatants of HPMECs were collected and assayed by sandwich ELISA kits according to the manufacturer's instruction. The minimum detection limit of the assay was $2 \mathrm{pg} / \mathrm{ml}$ of protein. ELISA kits for IL-6 and IL-8 were obtained from eBiosciences. The absorbance was measured at $450 \mathrm{~nm}$. The levels of IL-6 and IL- 8 were generated from a standard curve. 
Real time reverse transcriptase-polymerase chain reaction (RT-PCR)

RT-PCR was used to detect IL-6 and IL-8 mRNA levels. HPMECs were treated 15 min prior to addition of LPS. After $1 \mathrm{~h}$, total cellular mRNA was extracted from $1.5 \times$ $10^{6}$ cells using RNeasy Mini Kit (Qiagen, Valencia, CA) according to the manufacture's protocol. The RNA concentrations were determined by the $\mathrm{OD}_{260}$ and $\mathrm{OD}_{260 / 280}$ values that were measured with spectrophotometer. Two microgram of total RNA was reverse transcribed to cDNA and reverse transcription was performed at $42^{\circ} \mathrm{C}$ for 30 min and followed by incubation at $85^{\circ} \mathrm{C}$ for $5 \mathrm{~min}$. For quantitative PCR, the $10 \mu \mathrm{l}$ reaction mixture contained $1 \mu 1$ of cDNA template, $3 \mu \mathrm{l}$ of $\mathrm{H}_{2} \mathrm{O}, 1 \mu \mathrm{l}$ of $10^{\prime}$ primer, $5 \mu \mathrm{l}$ of $2 \times$ Taq PCR Master-mix. DNA samples were analyzed for cDNA of IL-6, IL-8 and GADPH by PCR amplification using specific primers. The primer sequences used for PCR were designed using Primer 5 software. The primers were as follows: for IL-6: sense: $5^{\prime}$ - AGG GCT CTT CGG CAA ATG TA - 3' and anti-sense: 5'- GAA GGA ATG CCC ATT AAC AAC AA - 3'; for IL-8: sense: 5'-ATT TCT GCA GCT CTG TGT GAA GGT GC-3' and anti-sense: 5' - TTG TGG ATC CTG GCT AGC AGA C-3'; for GADPH: sense: 5' - CGG AGT CAA CGG ATT TGG TC $-3^{\prime}$ and anti-sense: $5^{\prime}$ - CGG TGC CAT GGA ATT TGC CA $-3^{\prime}$. The PCR was started at $95^{\circ} \mathrm{C}$ for $10 \mathrm{~min}, 40$ cycles of $95^{\circ} \mathrm{C}$ for $10 \mathrm{~s}$, followed by $60^{\circ} \mathrm{C}$ for $1 \mathrm{~min}$, and $72^{\circ} \mathrm{C}$ for $1 \mathrm{~min}$. The housekeeping gene GADPH was used for normalization. Relative quantification values were calculated by the $\Delta \Delta \mathrm{Ct}$ method.

\section{Immunofluorescence}

HPMECs were treated with UFH 15 min prior to addition of LPS. After $1 \mathrm{~h}$, cells were fixed in PBS containing 2\% paraformaldehyde and permeabilized in PBS containing $0.2 \%$ bovine serum albumin and $0.1 \%$ Triton $\mathrm{X}-100$ for $15 \mathrm{~min}$ at $4{ }^{\circ} \mathrm{C}$. Cells were cultured in blocking solution $(2 \mathrm{mg} / \mathrm{ml}$ human IgG and $0.5 \%$ bovine serum albumin) for $30 \mathrm{~min}$ at room temperature. Staining was performed in blocking solution with anti-NF- $\mathrm{kB}$ or antiIкB- $\alpha$ (Cell Signaling Technology, Beverly, MA) antibodies followed by secondary antibodies conjugated to phosphatidylethanolamine or FITC, respectively (Alexa 633 or Alexa 488, Molecular Probes, Eugene, OR). Nuclear staining was performed with $50 \mathrm{ng} / \mathrm{ml} \mathrm{4}{ }^{\prime} 6$ diamidino-2-phenylindole (DAPI, Sigma). The movement of fluorescent label for NF- $\mathrm{kB}$ was quantified by the percentage of its location.

\section{Whole-cell protein extraction and Immunoblotting}

Cells were treated with UFH 15 min prior to addition of LPS. After $1 \mathrm{~h}$, cells were lysed in ice-cold urea/CHAPS/ Tris buffer (8 M urea, $4 \%$ CHAPS, $40 \mathrm{mM}$ Tris- $\mathrm{HCl}$ containing DTT, $0.1 \mathrm{mM}$ phenylmethylsulfonyl fluoride,
$10 \mu \mathrm{g} / \mathrm{ml}$ of protease inhibitors and phosphatase inhibitors) for $15 \mathrm{~min}$ on ice with intermittent vortexing, and extracts were then centrifuged for $10 \mathrm{~min}$ at $14,000 \times g$. The supernatants were used for immunoblotting. Whole proteins in HPMECs were fractioned by $10 \%$ sodium dodecyl sulfate-polyacrylamide gel electrophoresis (SDSPAGE) and transferred onto Immobilon-P (Millipore) polyvinylidene difluoride (PVDF) membranes electrophoretically. Antibodies recognizing phospho-NF- $\kappa B$ p65 (Ser536), phospho-IкB- $\alpha$ (Ser32), phospho-p44/42 MAPK (Erk1/2) (Thr202/ Tyr204), phospho-p38 MAPK (Thr180/Tyr182), phospho-JNK MAPK (Thr183/ Tyr185), phospho-signal transducer and activator of transcription-3 (STAT3) (Tyr 705) were added at a 1: 1000 dilution (Cell Signaling Technology, Beverly, MA), whereas antibody to IKB- $\alpha$ was added at a 1:2000 dilution (Cell Signaling Technology, Beverly, MA), and antibody to $\beta$-actin was added at a 1:5000 dilution (Santa Cruz Biotechnology, CA). The primary antibody was examined by using autoradiographic film with an HRPconjugated secondary antibody and an ECL chemiluminescent system (Amersham Pharmacia Biotech, Piscataway, NJ). To prove equal protein loading on gels, $\beta$ actin was used as a standard. Secondary antibodies linked to horseradish peroxidase (HRP) and ECL were purchased from Amersham Biosciences. The intensity of immunoreactive bands was determined using Image $\mathrm{J}$ software (NIH).

\section{NF-KB DNA binding assay}

An ELISA-based NF- $\kappa B$ DNA binding assay was used to detect the activation of the $\mathrm{p} 65$ subunit of NF-kB in the nucleus according to the manufacturer's instruction (Active Motif, Carlsbad, CA). Briefly, a total of $7.5 \mu \mathrm{g} \mathrm{nu}-$ clear extract was prepared using the Nuclear Extraction Kit (Active Motif). Nuclear extracts containing equal amounts of protein were added to the precoated (NF$\kappa B$-specific oligonucleotide) 96 -well plate. The plate was incubated for $1 \mathrm{~h}$ at RT. After three washings of the plate, a primary antibody specific for NF- $\mathrm{kB} / \mathrm{p} 65$ was added and the plate was incubated for $1 \mathrm{~h}$ at RT. After washing three times to remove excess primary antibody, an HRP conjugated secondary antibody was added to each well and incubated for $1 \mathrm{~h}$. Plates were read at 450 $\mathrm{nm}$ after addition of the developing reagent.

\section{Statistical analysis}

Data analysis was evaluated by using SPSS 18.0 software. Data were described as mean \pm SD from at least three replicates. The results were analyzed by ANOVA with multiple comparisons, and then by student's paired ttest. The $p$-values lower than 0.05 were considered statistically significant. 

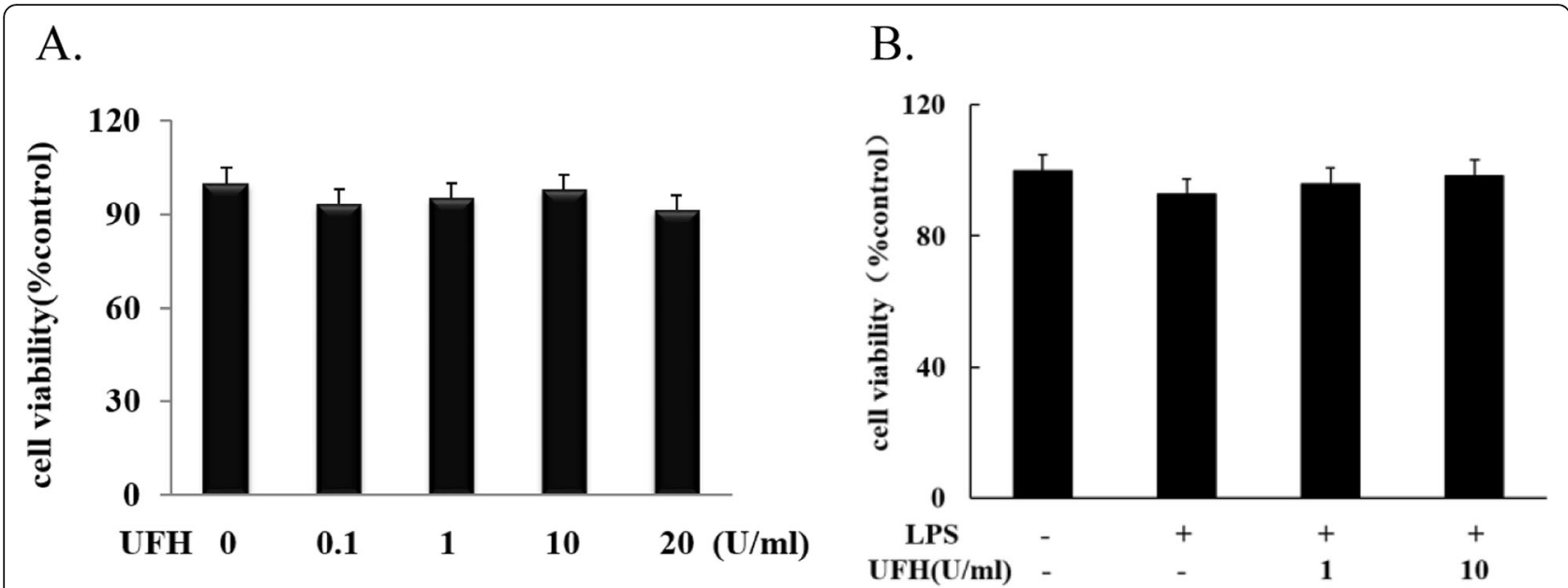

Fig. 1 Effect of UFH on cell viability measured by MTT asssay. a Cells were treated with $0.1 \%$ DMSO or UFH for $24 \mathrm{~h}$. b Cells were pre-treated with UFH ( 1 and $10 \mathrm{U} / \mathrm{ml}$ ) for $15 \mathrm{~min}$ and then exposed to $10 \mu \mathrm{g} / \mathrm{ml}$ of LPS for $24 \mathrm{~h}$. Values are means \pm SD of three independent experiments

\section{Results}

Effect of UFH on LPS-induced HPMECs injury

As cell viability is the most direct indicator to show the cell state, the effects of UFH on viability of LPSstimulated HPMECs were evaluated. No difference was seen in cell viability between cells treated with UFH $(0.1-20 \mathrm{U} / \mathrm{ml})$ alone and controls (Fig. 1a). The results showed that UFH less than the concentration $(0.1-20 \mathrm{U} /$ $\mathrm{ml}$ ) had no detrimental effect on cells. Pre-treatment of HPMECs with various concentrations of UFH (1-10 U/ $\mathrm{ml}$ ) markedly increased the viability of LPS-stimulated HPMECs (Fig. 1b).

\section{Transfection}

In order to further prove the involvement of NF- $\mathrm{BB}$ pathway. We conducted transfection to silence IKB- $\alpha$.

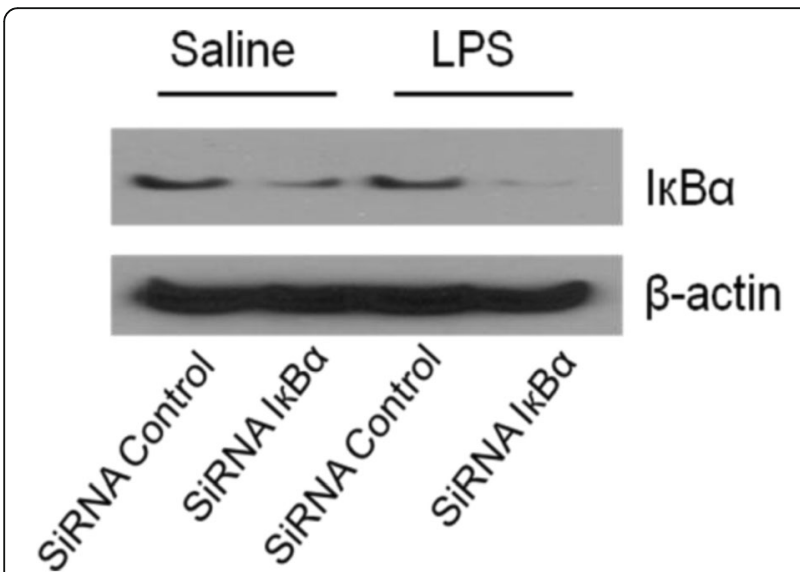

Fig. 2 Western blot to prove successful transfection. The results are representative of three independent experiments
We performed western blot (Fig. 2) and immuno fluorescence (Fig. 3) to prove successful transfection.

\section{UFH inhibits LPS-induced nuclear translocation of NF-KB by immunofluorescence}

Since NF- $\mathrm{kB}$ is a vital element participating in the inflammatory response, we further proved the involvement of NF- $\mathrm{kB}$ for the pro-inflammatory mediator suppression in LPS-induced HPMECs injury. We determined the effects of UFH on the nuclear translocation of NF- $\mathrm{kB}$ p65 subunit. NF- $\mathrm{kB}$ existed mostly in the cytoplasm in untreated cells, LPS at the concentration of $10 \mu \mathrm{g} / \mathrm{ml}$ strongly enhanced the nuclear translocation of NF-kB. Remarkably, pre-treatment with UFH retained the NF-kB in the cytosol even when addition of LPS (Fig. 3a). UFH also inhibited

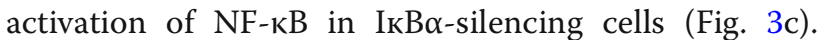
Taken together, the results show that UFH possibly has an anti-inflammatory effect in part by interfering with NF- $k B$ signaling pathway.

Effect of UFH on IL-6 and IL-8 production induced by LPS The effect of UFH on LPS-stimulated pro-inflammatory cytokines release was measured at $3 \mathrm{~h}$ after LPS stimulation. LPS $(10 \mu \mathrm{g} / \mathrm{ml})$ raised the levels of IL- 6 and IL- 8 in supernatants. As expected, more inflammatory mediators were released in IKB $\alpha$-silencing group. UFH decreased LPS-stimulated IL-6 and IL-8 expressions especially in the $10 \mathrm{U} / \mathrm{ml}$ group (Fig. 4a).

\section{UFH depresses LPS-induced IL-6 and IL-8 mRNA expressions}

Expressed mRNA levels of IL-6 and IL-8 in HPMECs from three independent experiments were evaluated by real-time PCR. Productions of IL- 6 and IL- 8 were found 


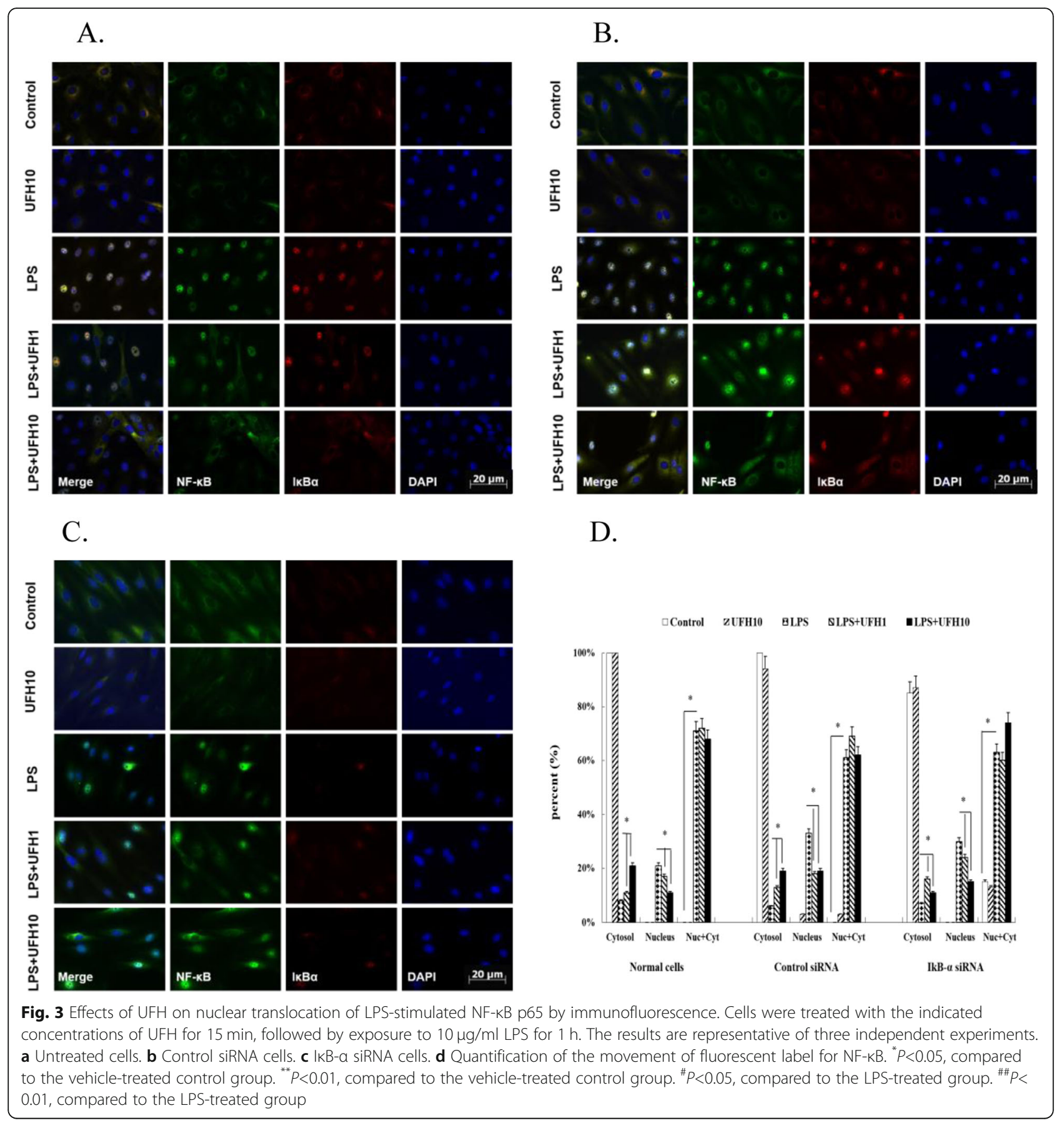

to be low in control group, obviously elevated after LPS stimulation. Increased expressions by LPS were significantly decreased by UFH pre-treatment, particularly at the concentration of $10 \mathrm{U} / \mathrm{ml}$ (Fig. $4 \mathrm{~b}$ ).

\section{Effects of UFH on LPS-induced MAPK activation}

We detected the possible mechanisms for IL-6 and IL-8 suppression in LPS-induced HPMECs injury by evaluating the effects of UFH on several signaling pathways. The cells were treated with UFH $(10 \mathrm{U} / \mathrm{ml})$ for $15 \mathrm{~min}$ before addition of LPS $(10 \mu \mathrm{g} / \mathrm{ml})$ for $1 \mathrm{~h}$. As shown in Fig. 5, LPS induced phosphorylation of $\mathrm{p} 38$, ERK1/2 and JNK MAPK. UFH treatment blocked MAPK activation in LPS-stimulated HPMECs. UFH also inhibited MAPK activation in IкB- $\alpha$-silencing cells.

\section{UFH inhibits LPS-induced activation of NF-KB through} inhibition of the degradation of IKB- $a$

MAPKs play important roles in the activation of NF- $k B$. We further investigated the effect of UFH on the nuclear 

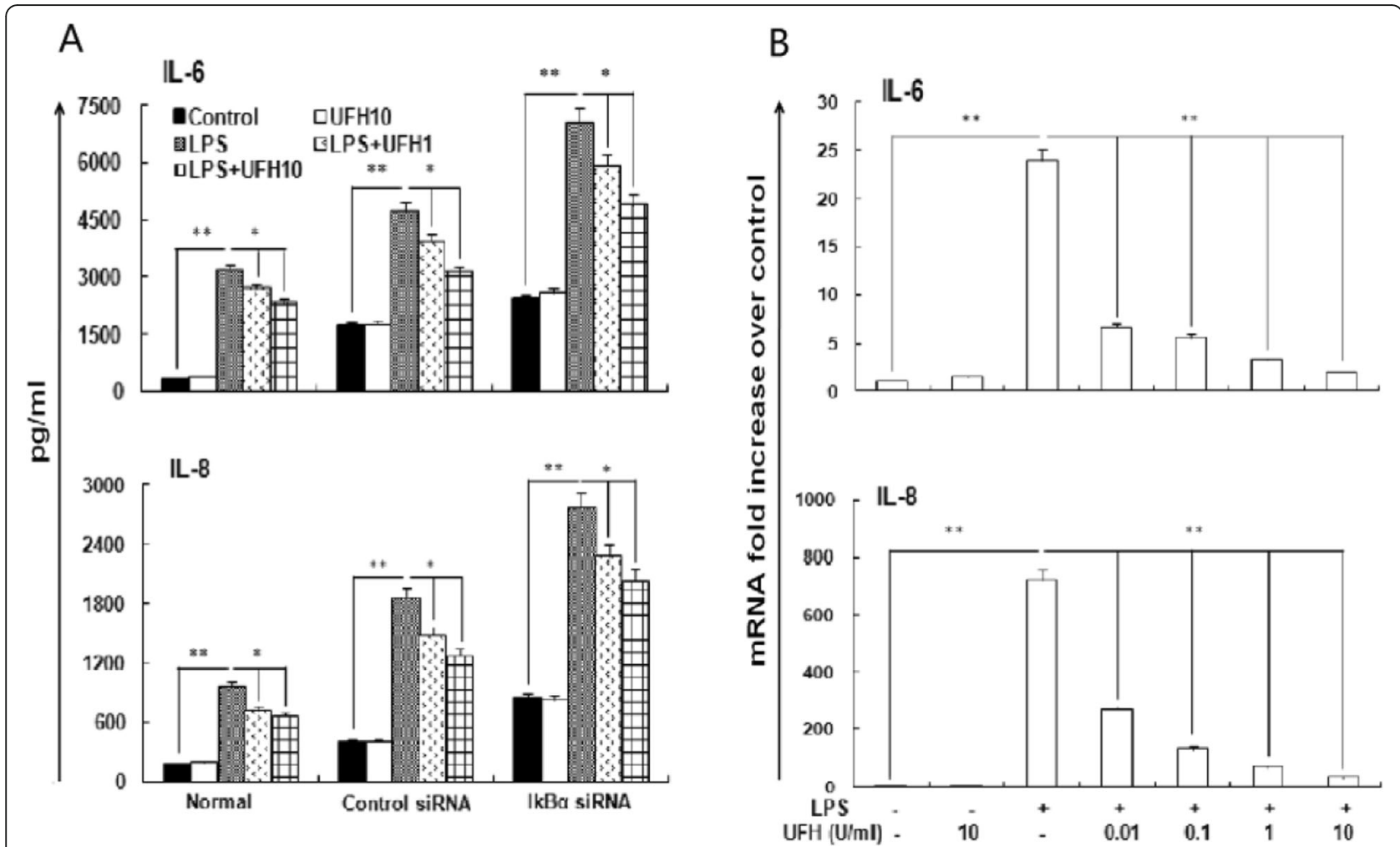

Fig. 4 Effects of UFH on the production of IL-6 and IL-8 stimulated by LPS. Supernatants and cells for evaluation of IL-6 and IL-8 were collected at indicated time. UFH suppressed the increasing effects of LPS both on protein (Fig. 4a) and mRNA levels (Fig. 4b). The results represent mean \pm SD of three replicates. ${ }^{*} P<0.05$, compared to the vehicle-treated control group. ${ }^{* *} P<0.01$, compared to the vehicle-treated control group. ${ }^{\#} P<0.05$, compared to the LPS-treated group. ${ }^{\#} P<0.01$, compared to the LPS-treated group

translocation of NF-kB by western blot. IkB- $\alpha$-silencing induced more obvious activation of NF-kB. LPS significantly increased the nuclear translocation of NF$\kappa B$. Pre-treatment of UFH retained the NF- $\kappa B$ in the cytoplasm. We next examined the effect of UFH on degradation of I $\mathrm{\kappa B}-\alpha$ in LPS-stimulated HPMECs, UFH notably inhibited degradation of IкB- $\alpha$ (Fig. 5). UFH also inhibited activation of NF-kB in IкB $\alpha-$ silencing cells. These results further showed that UFH exerts an anti-inflammatory effect by interfering with the NF-кB-mediated pathway.

\section{Effect of UFH on LPS-induced STAT3 activation}

There may be different transcription factors involved in cytokine expression besides NF- $\kappa \mathrm{B}$. Here we examined the effect of UFH on LPS-induced STAT3 activation in HPMECs. As shown in Fig. 5, STAT3 activation by LPS was also inhibited by UFH in the concentration of $10 \mathrm{U} /$ $\mathrm{ml}$ in both normal and ІкB- $\alpha$-silencing cells. These results suggest that UFH exerts protective effect on LPSinduced inflammatory response in HPMECs through different pathways.

\section{UFH inhibits LPS-induced NF-KB DNA binding activity}

Actually, activation of NF- $\mathrm{kB}$ does not necessarily mean that NF- $\mathrm{kB}$ has transcriptional activity. We then performed DNA binding to examine the involvement of NF-kB. As a result, UFH obviously inhibited NF-kB DNA binding activity (Fig. 6).

\section{Discussion}

A continuous barrier of vascular endothelium lined in the inner surface of quiescent blood vessels [11]. Normally, endothelium plays an anticoagulant effect to maintain the homeostasis of the blood system. After being invaded by pathogen, it changes into procoagulant surface to promote the formation of microthrombi [12]. Furthermore, endothelial cells are involved in the process of sepsis as inflammatory cells [13]. When bacteria invade the body, systemic inflammatory reaction leads to cytokine production and endothelial cells activation and injury [14]. The activated endothelium undergoes structural and functional changes, which cause leakage of intravascular components, interaction of leukocytes and endothelial cells and coagulation 

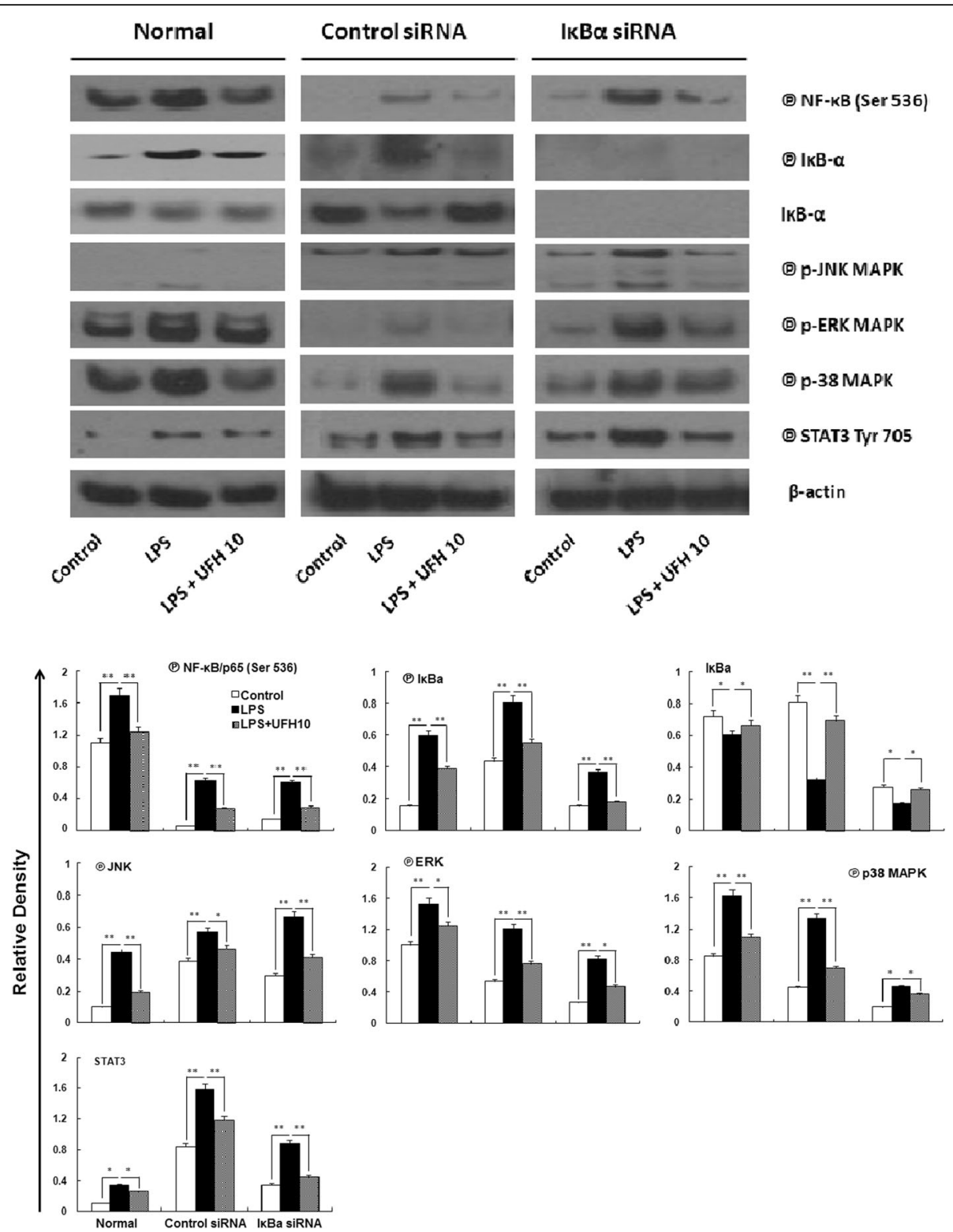

Fig. 5 Effects of UFH on LPS-stimulated activation of different signaling pathways. Cells were treated with $10 \mathrm{U} / \mathrm{ml}$ of UFH for $15 \mathrm{~min}$, followed by exposure to $10 \mu \mathrm{g} / \mathrm{ml}$ LPS for $1 \mathrm{~h}$. The intensity of the band was corrected with that of $\beta$-actin. Graph shows mean \pm SD fold change over control from 3 experiments. ${ }^{*} P<0.05$, compared to the vehicle-treated control group. ${ }^{* *} P<0.01$, compared to the vehicle-treated control group. ${ }^{\#} P<0.05$,

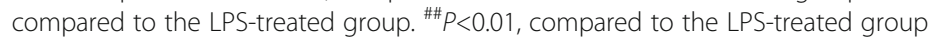

activation [2]. Thus, endothelial cells acts as first-line responders against invading pathogens in the progress of sepsis [15].

LPS-induced injury of endothelial cells leads to the initiation of proximal signaling events, which lead to the enhanced transcription and expression of pro-inflammatory mediator messenger RNA [16]. Our previous report has shown that UFH has anti-inflammatory properties on LPS-induced HPMECs injury possibly through NF-kB pathway [8-10]. However, the underlying mechanisms to explain the anti-inflammatory effect of UFH remain to be elucidated. Therefore, in this study we exposed the IkB- $\alpha$ silencing HPMECs to LPS. In vitro, UFH reduced the production of IL-6 and IL-8. Moreover, UFH inhibited LPSinduced NF- $\kappa B$ activation, including degradation of IкB- $\alpha$ and nuclear translocation of p65 even in IkB- $\alpha$-silencing HPMECs. Our findings further proved the involvement of NF- $\mathrm{KB}$ signaling pathway in the protective effects of UFH on LPS-stimulated endothelial cells as our previous reports. These results are also consistent with in vivo experiment which showed the anti-inflammatory effect of UFH via inactivation of NF-kB pathway [17-19]. 


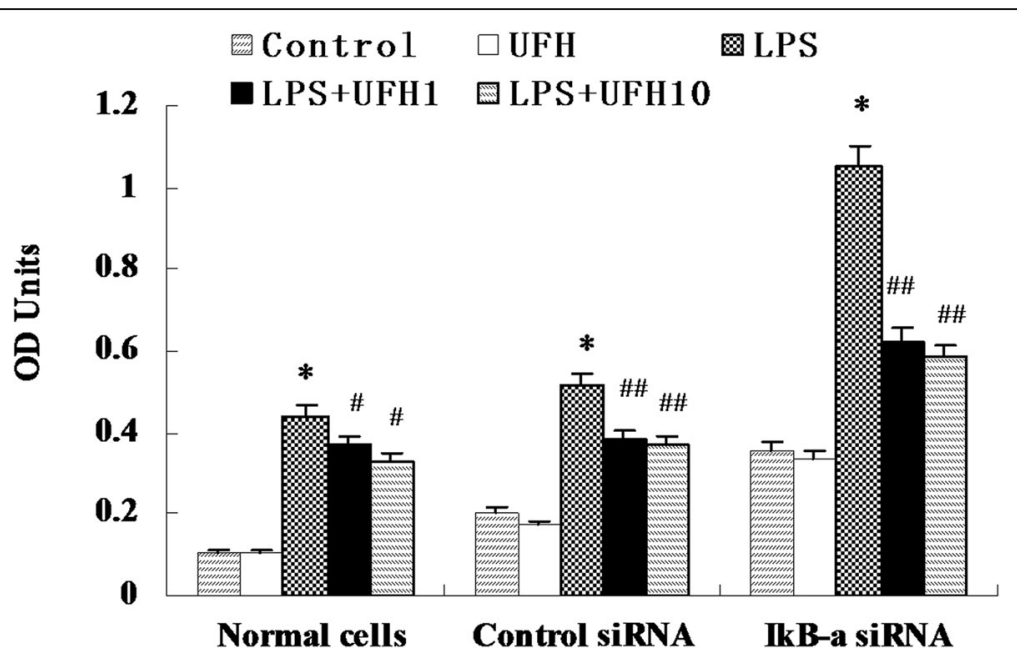

Fig. 6 Effects of UFH on LPS-induced NF-KB DNA binding. Cells were pretreated with $10 \mathrm{U} / \mathrm{ml}$ of UFH for $15 \mathrm{~min}$, followed by exposure to $10 \mu \mathrm{g} /$ $\mathrm{ml}$ LPS for $1 \mathrm{~h}$. The results are representative of three independent experiments. ${ }^{*} P<0.05$, compared to the vehicle-treated control group. ${ }^{* *} P<0.01$, compared to the vehicle-treated control group. ${ }^{\#} P<0.05$, compared to the LPS-treated group. ${ }^{\#} P<0.01$, compared to the LPS-treated group

Though NF-kB commonly participates in the transcriptional up-regulation of pro-inflammatory mediators, some experiments indicate that increases in cytokine production may be also caused by different transcription factors, such as MAPK, STAT3, AP-1 [20]. Here we demonstrated that pre-incubation with UFH blocked the LPS-induced phosphorylation of STAT3 in both normal and IKB- $\alpha$-silencing cells. And pre-incubation with UFH significantly inhibited LPS-stimulated MAPK activation by the inhibition of phosphorylated p38、ERK $1 / 2$ and JNK levels in both normal and IKB- $\alpha$-silencing cells. These hallmark features totally offer proof for the involvement of MAPK, NF- $\mathrm{BB}$ and STAT3 signaling pathway in HPMECs stimulated by LPS. Hence, the modulation of these events by UFH explains its protective effect against LPS-stimulated expression and release of proinflammatory mediators. Thus, based on present data, it is probably that UFH exerts its anti-inflammatory effects on LPS-induced HPMECs injury by inhibiting the activation of receptor-mediated signaling pathways, involving MAPK、NF-kB and STAT3. Further research is needed to find out which is the main pathway.

As for the down-regulation of the mentioned pathway in our experiments could be explained by interference with TLR4 ligand binding. Anastase-Ravion et al. [21] had shown that heparin inhibits the binding of LPS to cells via a CD14-independent pathway. We observed LPS-RS (an antagonist for TLR4) inhibited LPS-induced up-regulation of IL-6 and G-CSF. UFH might take its therapeutic effect through TLR4-dependent pathway [22].

\section{Conclusion}

In this study, we further proved the molecular mechanisms involved in the anti-inflammatory effects of UFH on LPS-induced HPMECs injury. These protective responses seem to be mediated by blocking of the proinflammatory MAPK、NF- $\mathrm{B}$ 、STAT3 signaling pathways. In terms of clinical relevance, these data collectively suggest that UFH might be a promising agent for the therapy of sepsis.

\section{Abbreviations}

DMSO: Dimethyl sulfoxide; ECGS: Endothelial cell growth supplement; ECM: Endothelial cell medium; ELISA: Enzyme-linked immunosorbent assay; FBS: Fetal bovine serum; HPMEC: Human pulmonary microvascular endothelial cells; IL: Interleukin; IKB-a: Inhibitor KB-a; LPS: Lipopolysaccharide; MAPK: Mitogen-activated protein kinase; MODS: Multiple organ dysfunction syndrome; MTT: Methyl thiazoyltetrazolium; NF-kB: Nuclear factor-kB; PBS: Phosphate-buffered saline; RT-PCR: Real time reverse transcriptasepolymerase chain reaction; STAT3: Signal transducer and activator of transcription-3; UFH: Unfractionated heparin

\section{Acknowledgements}

Not applicable.

\section{Authors' contributions}

Conceptualization, $X \mathrm{~L}$ and $\mathrm{XM}$; Data curation, $\mathrm{LL}$ and $\mathrm{YS}$; Funding acquisition, $\mathrm{XL}$; Investigation, XL, LL, YS and SY; Software, LL; Writing - original draft, XL; Writing review \& editing, XM. All authors read and approved the final manuscript.

\section{Funding}

The research discussed unfractionated heparin was supported by the National Natural Science Foundation of China (Grant No. 81671936).

\section{Availability of data and materials}

The data used to support the findings of this study are available from the corresponding author upon request.

Ethics approval and consent to participate Not applicable.

Consent for publication

Not applicable.

Competing interests

The authors declare that they have no competing interests. 
Received: 12 November 2019 Accepted: 27 January 2020

Published online: 10 February 2020

\section{References}

1. Iba T, Levy JH. Inflammation and thrombosis: roles of neutrophils, platelets and endothelial cells and their interactions in thrombus formation during sepsis. J Thromb Haemost. 2018;16(2):231-41.

2. Opal SM, van der Poll T. Endothelial barrier dysfunction in septic shock. J Intern Med. 2015;277(3):277-93.

3. Levi M, Van der Poll T, Büller HR. Bidirectional relation between inflammation and coagulation. Circulation. 2004;109:2698-704.

4. Onishi A, St Ange K, Dordick JS, Linhardt RJ. Heparin and anticoagulation. Front Biosci (Landmark Ed). 2016;21:1372-92.

5. Ludwig RJ. Therapeutic use of heparin beyond anticoagulation. Curr Drug Discov Technol. 2009:6:281-9.

6. Young E. The anti-inflammatory effects of heparin and related compounds. Thromb Res. 2008;122:743-52.

7. Li X, Ma X. The role of heparin in sepsis: much more than just an anticoagulant. Br J Haematol. 2017;179(3):389-98.

8. Li X, Zheng Z, Li X, Ma XC. Unfractionated heparin inhibits lipopolysaccharide-induced inflammatory response through blocking p38 MAPK and NF-KB activation on endothelial cell. Cytokine. 2012:60:114-21.

9. Li X, Li X, Zheng Z, Ma XC. Unfractionated heparin suppresses lipopolysaccharide-induced monocyte chemoattractant protein-1 expression in human microvascular endothelial cells by blocking Krüppel-like factor 5 and nuclear factor-kB pathway. Immunobiology. 2014;219:778-85.

10. Li X, Liu YN, Wang L, Li ZL, Ma XC. Unfractionated heparin attenuates LPSinduced IL-8 secretion via PI3K/Akt/NF-kB signaling pathway in human endothelial cells. Immunobiology. 2015;220:399-405.

11. Rajendran P, Rengarajan T, Thangavel J, Nishigaki Y, Sakthisekaran D, Sethi $\mathrm{G}$, Nishigaki I. The vascular endothelium and human diseases. Int J Biol Sci. 2013;9(10):1057-69.

12. Ince C, Mayeux PR, Nguyen T, Gomez H, Kellum JA, Ospina-Tascón GA Hernandez G, Murray P, De Backer D, ADQI XIV Workgroup. The endothelium in sepsis. Shock. 2016:45(3):259-70.

13. Wenzel RP. Treating sepsis. N Engl J Med. 2002;347:966-7.

14. Cinel I, Dellinger RP. Advances in pathogenesis and management of sepsis. Curr Opin Infect Dis. 2007;20:345-52.

15. Aird WC. The role of the endothelium in severe sepsis and multiple organ dysfunction syndrome. Blood. 2003;101:3765-77.

16. Medzhitov R. Toll-like receptors and innate immunity. Nat Rev Immunol. 2001;1:135-45.

17. Li X, Li ZL, Zheng Z, Liu YN, Ma XC. Unfractionated heparin ameliorates lipopolysaccharide-induced lung inflammation by downregulating nuclear factor-KB signaling pathway. Inflammation. 2013;36:1201-8.

18. Zhao DM, Ding RY, Mao YR, et al. Heparin rescues sepsis-associated acute lung injury and lethality through the suppression of inflammatory responses. Inflammation. 2012;35(6):1825-32.

19. Chen S, Zhang XJ, Sun YN, et al. Unfractionated heparin attenuates intestinal injury in mouse model of sepsis by inhibiting heparanase. Int Clin Exp Pathol. 2015;8(5):4903-12.

20. Farwell SL, Kanyi D, Hamel M, Slee JB, Miller EA, Cipolle MD, Lowe-Krentz LJ. Heparin decreases in tumor necrosis factor a (TNFa)-induced endothelia stress responses require Transmembrane protein 184A and induction of dual specificity phosphatase 1. J Biol Chem. 2016;291(10):5342-54

21. Anastase-Ravion S, Blondin C, Cholley B, Haeffner-Cavaillon N, Castellot JJ, Letourneur D. Heparin inhibits lipopolysaccharide (LPS) binding to leukocytes and LPS-induced cytokine production. J Biomed Mater Res A 2003:66(2):376-84

22. Li X, Liu YN, Ma XC. Unfractionated heparin inhibits lipopolysaccharideinduced expression of granulocyte colony-stimulating factor in human endothelial cells through Toll-like receptor 4 signaling pathway. Zhonghua Wei Zhong Bing Ji Jiu Yi Xue. 2015;27(2):81-5.

\section{Publisher's Note}

Springer Nature remains neutral with regard to jurisdictional claims in published maps and institutional affiliations.

Ready to submit your research? Choose BMC and benefit from:

- fast, convenient online submission

- thorough peer review by experienced researchers in your field

- rapid publication on acceptance

- support for research data, including large and complex data types

- gold Open Access which fosters wider collaboration and increased citations

- maximum visibility for your research: over $100 \mathrm{M}$ website views per year

At $\mathrm{BMC}$, research is always in progress.

Learn more biomedcentral.com/submissions 